\title{
Determination of Trace Toxic Metal (As, Cd, Pb) in Freshwater Fish of Vietnam by ICP-MS
}

\author{
Quang Hieu Tran,", Kim-Phuong Pham ${ }^{2}$ \\ ${ }^{1}$ Department of Chemistry, Basic Sciences Department, Saigon Technology University, 180 Cao Lo, District 8, Ho Chi Minh City \\ 700000, Vietnam. \\ ${ }^{2}$ Saigon STC Hi-tech Analytical Center, Ho Chi Minh City 700000, Vietnam.
}

How to cite this paper: Quang Hieu Tran, Kim-Phuong Pham. (2021) Determination of Trace Toxic Metal (As, Cd, Pb) in Freshwater Fish of Vietnam by ICP-MS. International Journal of the Science of Food and Agriculture, 5(1), 163-169.

DOI: $10.26855 /$ ijfsa.2021.03.020

Received: December 10, 2020

Accepted: February 28, 2021

Published: March 11, 2021

*Corresponding author: Quang Hieu Tran, Department of Chemistry, Basic Sciences Department, Saigon Technology University, 180 Cao Lo, District 8, Ho Chi Minh City 700000, Vietnam. Email: hieu.tranquang@stu.edu.vn https://orcid.org/0000-0003-0644-1002

\begin{abstract}
This research aimed to determine the concentration levels of three toxic metals (lead, cadmium, arsenic) in fresh fish. Inductively coupled plasma-mass spectrometry (ICP-MS) was used to determine lead, cadmium, and total arsenic. Liquid chromatography coupled with ICP-MS was used for arsenic speciation. Limit of detection (LOD), limit of quantification (LOQ) were: 0.073 and $0.22 \mu \mathrm{g} / \mathrm{L}$ for As, 0.05 and $0.16 \mu \mathrm{g} / \mathrm{L}$ for $\mathrm{Cd}, 0.09$ and $0.27 \mu \mathrm{g} / \mathrm{L}$. The recoveries were as follows: 89.12\% for As, $92.13 \%$ for $\mathrm{Cd}$, and $\mathbf{9 7 . 2 1 \%}$ for Pb. Intra-assay precision levels were between 1.53 and $3.18 \%$. Inter-assay precision levels were between 2.43 and $4.91 \%$. The toxic metal concentration in the muscle of fish ranged from 2.22 $\pm 0.16 \mu \mathrm{g} / \mathrm{kg}$ for As, $1.38 \pm 0.21$ to $3.59 \pm 0.19 \mu \mathrm{g} / \mathrm{kg}$ for Cd, $16.25 \pm 1.09$ to $16.25 \pm 1.09 \mu \mathrm{g} / \mathrm{kg}$ for $\mathrm{Pb}$. The toxic metal concentrations in fish muscle were lower than the permitted level set by the Ministry of Health Vietnam and Food and Drug agent.
\end{abstract}

\section{Keywords}

Toxic metal, Asenic, lead, cadmium, ICP-MS

\section{Introduction}

The metals of particular concern associated with adverse health effects are lead (Pb), cadmium (Cd), and arsenic (As). Lead is often referred to as a "heavy metal" because of its large atomic mass [1]. The toxicity of these metals can be divided into two main aspects: (i) The fact that they have no known metabolic function, but their presence in the body disrupts cellular processes leading to toxicity in some organs; (ii) Potential, especially lead-heavy metals, accumulate in biological tissues through an accumulation process known as bioaccumulation [2]. This occurs because the metal, when introduced into the body, is stored in organs such as the liver or kidneys and is excreted at a rate slower than its absorption. This metal bioaccumulation occurs in all animals, including food animals such as fish and cattle, as well as in humans. Therefore, it is necessary to control these toxic metals in food to protect human health.

Biologically, As is a highly toxic metal that can cause 19 different diseases, including skin and lung cancer; on the other hand, arsenic plays a role in nuclein exchange, protein synthesis, and hemoglobin. The effects of As on organisms, especially fish, have been studied. Research results of Tanu Allen et al. (2004) on Channa punctatus fish after $\mathrm{As}_{2} \mathrm{O}_{3}$ contamination for 90 days, As content in liver, kidney, gills, and meat increased to day 60 and then decreased at day 90 . Moreover, when fish is contaminated with As, the content of lipid peroxidation and reduced glutathione will be increased on day 07 and then decreased at day 60, and then increased at day 90 [3]. Tanu Allen et al. (2004) have also studied Channa punctatus fish after contamination with $\mathrm{As}_{2} \mathrm{O}_{3}$ for 60 days. The levels of turned glutathione, reduced glutathione, and oxidized glutathione in the liver and kidneys have increased similar to that of Asb in these organs [4]. Sangeeta Das et al. (2012) polluted Channa punctatus fish with $\mathrm{NaAsO}_{2}$, showing that the liver is the main organ affected by arsenic because it plays an important role in absorption, metabolism, accumulation, and digging arsenic release. $\mathrm{NaAsO}_{2}$ is the cause that affects DNA cleavage and replication in the liver [5]. Joseph R. Shaw et al. (2007) stu- 
died the effect of arsenic on fish Fundulus heterolitus. The results were consistent with predicting that the gene multidrug resistance-associated protein (MRP) for arsenic transport to glutathione binding in the liver has increased [6]. The study of Jeng-Wei Tsai et al. (2012) on Oreochromis mossambicus fish, which was As contaminated, showed that fish's health and growth rate decreased with increased pollution duration and As concentration in polluted water [7]. Bibha Kumari and Jawaid Ahsan reported that As was responsible for the reduced ability to convert glycogen to glucose in Clarias batrachus fish’s meat[8].

Cadmium is not an essential metal, has no biological functions but is highly toxic. This metal accumulates inactive metabolic tissues, causing tissue damage, spinal abnormalities, respiratory disorders [9]. Besides, cadmium also affects the reproduction and development of some fish species [1] [10]. Cadmium leads to the increasing of blood glucose, hypokalaemia, and increasing membrane permeability [11]. Furthermore, cadmium caused changes in glutathione levels and affected the intracellular thiol function [12]. Several studies also showed cadmium is related to an increase or decrease in GSH levels in organisms [13] [14].

The toxic effects of lead have been studied in people who are exposed to lead during their work. Short-term exposure to high lead levels can cause brain damage, paralysis, anemia, and digestive symptoms. Long term exposure can damage kidneys, reproductive function, and immune system. The most serious impact of low lead exposure is intellectual development in young children. Lead crosses the placental barrier and accumulates in the fetus. Lead also accumulates in fish and shellfish and can also be found in higher organ foods (liver and kidney) in animals. O*. Ay et al. (1999) studied Tilapia zilii when contaminated with $\mathrm{Pb}\left(\mathrm{NO}_{3}\right)_{2}$, the activity of $\mathrm{Na}$, K-ATPase enzymes was inversely related to the $\mathrm{Pb}$ concentration in the environment [15]. Andrea Martini Ribeiro et al. (2014) studied the Prochilodus lineatus freshwater fish by contaminating $\mathrm{Pb}$ at different concentrations. Results showed that lead accumulated in all surveyed fish organs to accumulate kidney> gill> liver> blood and meat [16].

This work has developed and validated the quality criteria of ICP-MS for analyzing arsenic, cadmium, and lead levels in toxic metal spiked fish samples. This method has been applied to test these metal levels in 8 freshwater fish species (Oreochromis niloticus, Ctenopharyngodon idella, Neopterygii, Oreochromis sp.,...) that have been common in Vietnam.

\section{Methods}

\subsection{Chemical and instrumentations}

Analytical grade nitric acid (65\%), hydrogen peroxide (30\%), Cadmium, Lead, and Arsenic, stock standard solution (1,000 mg/L) were obtained from Merck (Darmstadt, Germany). The working standard solutions were freshly prepared by diluting a suitable aliquot of the standard stock solutions.

This work was conducted on Elan ICP-MS 6000 (Perkin Elmer) equipment. The ICP-MS data acquisition parameter has been installed followings: Scan mode: Peak hopping; point/mass: 1.0; resolution/amu: 0.7; sweeps/reading: 10; readings/replicates: 5; replicates: 11 ; integration time (s): 1.0 .

\subsection{Selection of analytical isotopes}

The selection of the appropriate isotope for each metal is vital for mass spectrometry. The instrument software will automatically select isotopes based on the intensity ratio between isotopes, less interfering elements, and high sensitivity. Table 1 presents isotopes and their intensity ratios.

Table 1. Isotopes and their intensities

\begin{tabular}{|c|c|c|}
\hline Elements & Isotopes & Intensity (\%) \\
\hline \multirow[t]{2}{*}{ As } & $75^{*}$ & 100 \\
\hline & 204 & 1.40 \\
\hline \multirow{6}{*}{$\mathrm{Pb}$} & 206 & 24.1 \\
\hline & 207 & 22.1 \\
\hline & $208^{*}$ & 52.4 \\
\hline & 106 & 1.25 \\
\hline & 108 & 0.89 \\
\hline & 110 & 12.49 \\
\hline \multirow{5}{*}{$\mathrm{Cd}$} & 111 & 12.8 \\
\hline & 112 & 24.13 \\
\hline & 113 & 12.22 \\
\hline & $114^{*}$ & 28.73 \\
\hline & 116 & 7.49 \\
\hline
\end{tabular}

*Isotope was selected for quantitative analyses. 


\subsection{Sample collection.}

Fish samples were purchased at traditional markets in District 8, Ho Chi Minh City. Samples were transferred to the laboratory, washed on the surface, packed with plastic bags, sealed, and frozen at $-10^{\circ} \mathrm{C}$ in the freezer.

\subsection{Sample treatment}

\subsubsection{Arsenic analysis}

Fish samples were separated from the flesh, gills, and liver. Each part was chopped and pureed. $5 \mathrm{~g}$ of sample was put in a crucible, added $5 \mathrm{ml}$ of $\mathrm{HNO}_{3}$, put on the $70-80^{\circ} \mathrm{C}$ in hot plate, and heated gently for about 30 minutes, then added $10 \mathrm{ml}$ of $5 \% \mathrm{Mg}\left(\mathrm{NO}_{3}\right)_{2}$. Next, the sample was heated at $550^{\circ} \mathrm{C}$ until complete ashes. The sample was cooled, dissolved by $20 \% \mathrm{HNO}_{3}$, and made up $50 \mathrm{ml}$ with $5 \% \mathrm{HNO}_{3}$ acid.

\subsubsection{Cadmium and lead analysis}

$5.0 \mathrm{~g}$ was added to the heat-resistant beaker, $25 \mathrm{ml}$ of $\mathrm{HNO}_{3}$ was added, and placed on the stove. The temperature has been slowly raised to $80^{\circ} \mathrm{C}$ to prevent the sample from splashing out. Until the smoke was free from rising, the sample was transferred to the furnace, at $450^{\circ} \mathrm{C}$, for 8 hours. After cooling, $20 \mathrm{ml}$ of $20 \% \mathrm{HNO}_{3}$ was added to dissolve the ash. The solution was made up of $50 \mathrm{ml}$ using $5 \% \mathrm{HNO}_{3}$.

\subsection{Method validation}

Calibration curves were constructed from standard stock solutions with initial concentrations of $10 \mathrm{mg} / \mathrm{L}$, which were diluted with $5 \% \mathrm{HNO}_{3}$ solution to obtain a standard series of 1, 5, 10, 25, 50, $100 \mu \mathrm{g} / \mathrm{L}$.

For the determination of LOD, LOQ, the experiment was carried as follows: the standard to the level of $5 \mathrm{ng} / \mathrm{g}$ was added to the sample. The measurement was conducted seven times to determine the standard deviation SD. The limited of detection and limited of quantitative are determined by the formula LOD $=3 \mathrm{xSD}$ and LOQ $=3 \mathrm{xLOD}$.

The recovery and precision were tested with three kinds of samples, which were spiked 60, 120 và $180 \mu \mathrm{g} / \mathrm{L}$. The sample was measured seven times for calculating SD, R\%, RSD\% at each level.

\section{Results and Discussions}

\subsection{Method validation}

The experiment was performed as presented in Section 2.5, the results have been processed to construct the standard curve equation. The standard curve equation of measurement for As was set as follows: $y=0.0005 x+0.0001$, for As; $y$ $=0.0007 \mathrm{x}+0.00004$, for $\mathrm{Cd}$, and $\mathrm{y}=0.00051 \mathrm{x}+0.0026$, for $\mathrm{Pb}$. All the correlation coefficients $\mathrm{R}^{2}$ reached over 0.999 .

Table 2. Recovery, intra-day repeatability, and inter-day repeatability of the method (at the sample contained As, $\mathrm{Cd}$, and $\mathrm{Pb}$ : 24.39, 3.56, and $25.61 \mathrm{mg} / \mathrm{kg}$, respectively)

\begin{tabular}{ccccccc}
\hline Element & LOD $(\mu \mathrm{g} / \mathrm{kg})$ & $\mathrm{LOQ}(\mu \mathrm{g} / \mathrm{kg})$ & RSD inter-days (\%) & RSD intra-days (\%) & Recovery (\%) & RSD (\%) \\
\hline $\mathrm{As}$ & 0.073 & 0.22 & 1.53 & 3.58 & 95.12 & 4.91 \\
$\mathrm{Cd}$ & 0.05 & 0.16 & 2.16 & 4.19 & 92.13 & 4.14 \\
$\mathrm{~Pb}$ & 1.02 & 3.01 & 3.18 & 5.31 & 101.21 & 2.43 \\
\hline
\end{tabular}

The results in Table 2 prove that the process of sample treatment and quantification of As, Cd, and Pb on ICP-MS equipment has high accuracy and sensitivity. The recoveries were as follows: $89.12 \%$ for As, 92.13\% for Cd, and 97.21\% for $\mathrm{Pb}$. The value of the relative standard deviation of RSD\% (2.43\% $\div 7.14 \%)$ showed that the difference between the measurements was negligible. These data also demonstrate that the sample matrix has not affected the analytical results. Thus, the ICP-MS method is very suitable to quantify the trace of As, $\mathrm{Cd}$, and $\mathrm{Pb}$ in fish samples.

The LOD and LOQ values of the measurement were as follows: $0.073 \mu \mathrm{g} / \mathrm{L}$ and $0.22 \mu \mathrm{g} / \mathrm{L}$ for As, 0.05 and $0.16 \mu \mathrm{g} / \mathrm{L}$ for $\mathrm{Cd}, 1.06$ and $3.20 \mu \mathrm{g} / \mathrm{L}$ for Pb. This result proves that the ICP-MS method is perfectly suited for determining trace amounts of metal in fish. The RSD\% value also determined intraday and inter-day reproducibility. These values demonstrated that this method had very high accuracy, repeatability, and stability.

\subsection{Trace of heavy toxic metal in fresh fish.}

\subsubsection{As level}

Table 3 shows that the As concentrations in all types of fish are not the same. This phenomenon proves that As accumulation in fish depends on the type and source of food. For example, grass carp, the food is mainly from plants, so the As content in the meat is lower than the rest of omnivorous fish. The As analysis results in this paper are also en- 
tirely consistent with some published authors. According to the Ministry of Health of Vietnam (200 ppb), the level of As in the fish samples above is below the permitted level. Results in Table 3 indicated that As accumulation in meat was significantly more than viscera and gills. This phenomenon has been explained by Reid and McDonald, who have demonstrated that the gill surface is negatively charged [17]. In the water environment, the As (III) ion exists as oxyanion $\mathrm{AsO}_{2}^{-}$, which negatively charges the electrostatic repulsion between the gills and the $\mathrm{AsO}_{2}^{-}$anion. Therefore, the accumulation of As in the gills is less than the remaining organs.

As accumulation in fish of this study is entirely consistent with previous publications. As is most accumulated in red tilapia [18] [19], catfish Silurus glanis [20] and carp [156]. As the accumulation of As in the flesh of 5 fish species living in Neretva, Croatia, was significantly greater than that of liver and gills [21].

We have used the HPLC-ICP-MS technique to determine the existing pattern of As in the sample. Chromatogram of the standard (Figure 1a) and the red tilapia sample (Figure 1b). The results showed that As only exists in organic forms, including AsB (78.4s), DMA (110.4s), MMA (649.3s). These substances are easily eliminated from the human body. Therefore, the existence of As in fish can be said to be safe for human consumption.
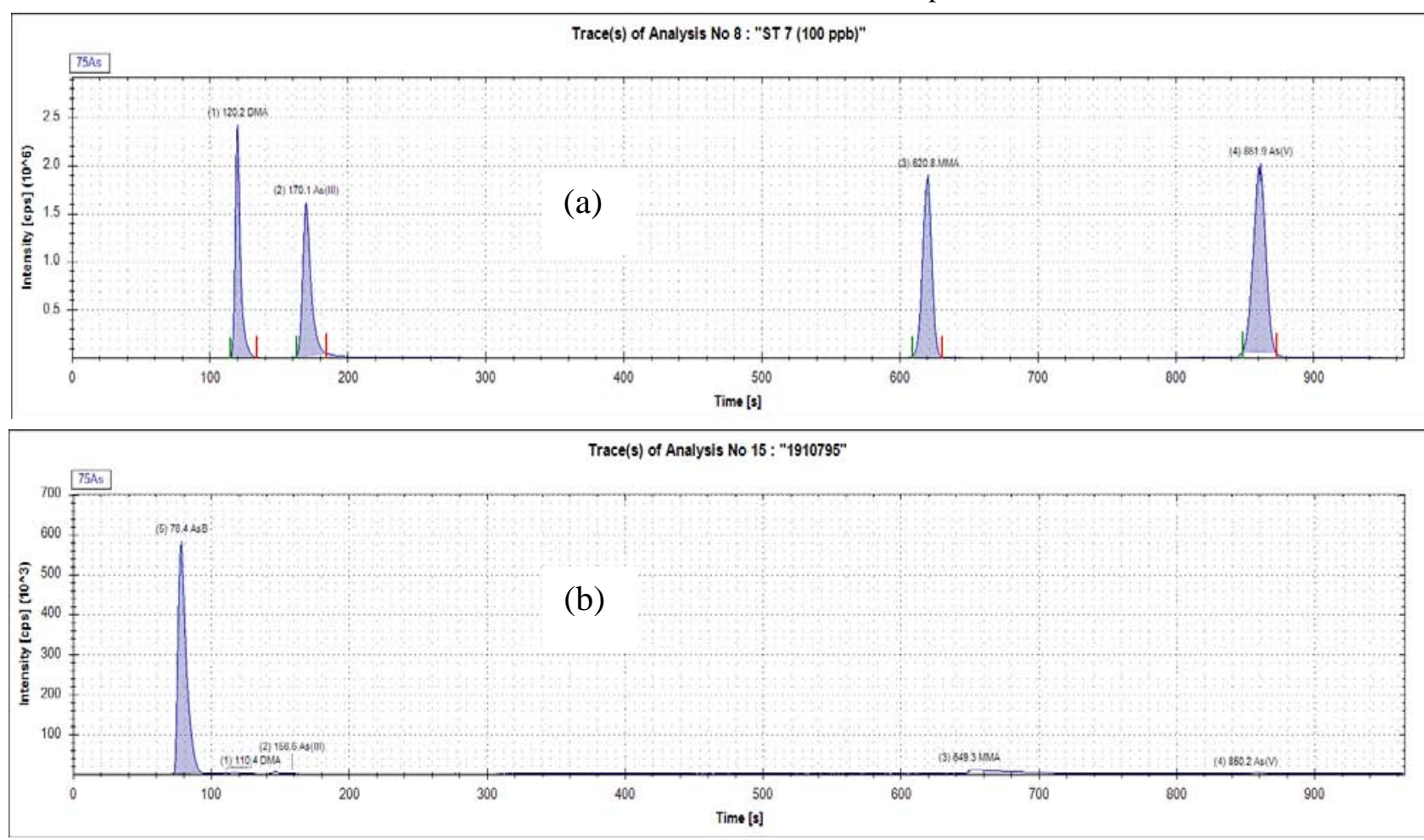

Figure 1. Chromatogram HPLC-ICP-MS of As 100 ppb standard (a) and red tilapia (b).

Table 3. As level in freshwater fish

\begin{tabular}{ccccc}
\hline Common name & Science name & Muscle tissues & Gill & Intestine \\
\hline Tilapia & Oreochromis niloticus & $9.29 \pm 0.14$ & $2.30 \pm 0.21$ & $10.23 \pm 1.07$ \\
Grass carp & Ctenopharyngodon idella & $2.22 \pm 0.16$ & $0.91 \pm 0.09$ & $2.28 \pm 0.29$ \\
Sesame fish & Neopterygii & $8.61 \pm 1.01$ & $2.34 \pm 0.32$ & $10.62 \pm 0.96$ \\
Red tilapia & Oreochromis sp. & $7.31 \pm 0.18$ & $12.34 \pm 1.69$ & $12.34 \pm 1.30$ \\
Snakehead & Channidae & $9.24 \pm 0.82$ & $5.43 \pm 0.26$ & $10.26 \pm 0.24$ \\
Carp fish & Cyprinus carpio & $6.29 \pm 0.92$ & $2.31 \pm 0.38$ & $7.22 \pm 2.65$ \\
\hline
\end{tabular}

\subsubsection{Cd level}

Cd content in fish meat, intestines, and gills are presented in Table 2. The results showed that the concentration of Cd increased in the order: fish meat $<$ fish gills <intestin. These data are also quite consistent with the previous publications. [22] [23]

Cd content in the analyzed samples was still much lower than the permitted threshold (50 ppb). In the body, metallo- 
thionein plays an important role in the detoxification of $\mathrm{Cd}^{2+}$ ions by forming a Cd-MT complex thanks to the association of the SH-group with cadmium ions to reduce the toxicity of $\mathrm{Cd}$. The liver is the organ playing the role of Cd-MT complex synthesis, and the liver also plays a role in storing $\mathrm{Cd}$ in the form of Cd-MT complex, Cd-glutathione, $\mathrm{Cd}$-cysteine, Cd-protein. Complex forms of $\mathrm{Cd}$ are transported by the blood to the kidneys for excretion with urine and feces [24]. Thang et al. have found Cd in a complex form with MT; when red walnut fish lived in Cd contaminated water, the rate of converting to Cd-MT complex in the liver was only $59.8 \%$ of the total concentration of Cd. In fish meat, Cd accumulates mainly in the form of Cd-MT complex (accounting for 85.3\%) [25]. The ratio of Cd-MT content to total Cd content depends only on the affinity of the meat tissue to the Cd-MT complex.

Table 4. Cd level in freshwater fish

\begin{tabular}{ccccc}
\hline Common name & Science name & Muscle tissues & Gill & Intestine \\
\hline Tilapia & Oreochromis niloticus & $2.89 \pm 0.61$ & $3.98 \pm 0.36$ & $4.80 \pm 0.81$ \\
Grass carp & Ctenopharyngodon idella & $3.59 \pm 0.19$ & $5.03 \pm 0.53$ & $5.34 \pm 0.32$ \\
Sesame fish & Neopterygii & $2.28 \pm 0.16$ & $2.72 \pm 0.19$ & $4.62 \pm 0.60$ \\
Red tilapia & Oreochromis sp. & $2.82 \pm 0.18$ & $3.45 \pm 0.36$ & $6.38 \pm 0.90$ \\
Snakehead & Channidae & $2.38 \pm 0.14$ & $3.21 \pm 0.39$ & $5.21 \pm 0.25$ \\
Carp fish & Cyprinus carpio & $1.38 \pm 0.21$ & $3.36 \pm 0.16$ & $6.22 \pm 2.65$ \\
\hline
\end{tabular}

\subsubsection{Pb level}

Analysis results of $\mathrm{Pb}$ content in the sample are presented in Table 5. For fish meat, lead content in fish meat ranges from 18.83 to $26.38 \mu \mathrm{g} / \mathrm{kg}$. The highest is in the red snapper and the lowest in the grass carp. Meanwhile, for fish intestines, the lead content in fish intestines ranges from $31.13 \div 49.22 \mu \mathrm{g} / \mathrm{kg}$. According to Decision No. 46/2007 / QD-BYT, the permissible Pb level in fish is $200 \mu \mathrm{g} / \mathrm{kg}$; the fish samples analyzed above were still within the safe limit for users. Table 5 also showed that $\mathrm{Pb}$ accumulation in fish gills was 1.5 to 2 times higher than meat and intestines. This result is also very consistent with red snapper research, $\mathrm{Pb}$ accumulation in gills more fish than other parts of the body [19][18]. Another study on $\mathrm{Pb}$ accumulation of Anabas testudien and Oreochromis auereus also showed significantly higher $\mathrm{Pb}$ levels in gills than liver [26] [27]. This phenomenon can be explained that the difference in function and structure of different parts of the body affects the biological accumulation of Pb. Carrying fish is part of direct contact with $\mathrm{Pb}$ in water. It also has a large and negatively charged surface area [17] [28], so it is always prone to cation absorption. This association plays an important role in $\mathrm{Pb}$ accumulation in gills and results in increased $\mathrm{Pb}$ accumulation in gills. $\mathrm{Pb}$ accumulation in meat is much lower than in the liver, which may be due to metabolic activities in the body. Some other studies also show that lead can bind to protein molecules with a small molecular weight such as metallothionein, delta-aminolevulinic acid dehydrates (ALAD), ... to reduce lead toxicity [29] [2].

Table 5. Pb level in freshwater fish

\begin{tabular}{ccccc}
\hline Common name & Science name & Muscle tissues & Gill & Intestine \\
\hline Tilapia & Oreochromis niloticus & $21.21 \pm 0.68$ & $42.81 \pm 0.91$ & $21.84 \pm 0.98$ \\
Grass carp & Ctenopharyngodon idella & $19.22 \pm 1.19$ & $35.01 \pm 1.42$ & $25.06 \pm 2.41$ \\
Sesame fish & Neopterygii & $16.25 \pm 1.09$ & $32.14 \pm 2.19$ & $29.14 \pm 1.24$ \\
Red tilapia & Oreochromis sp. & $18.83 \pm 1.01$ & $43.12 \pm 1.03$ & $23.13 \pm 1.17$ \\
Snakehead & Channidae & $26.38 \pm 1.17$ & $49.22 \pm 1.53$ & $31.24 \pm 1.41$ \\
Carp fish & Cyprinus carpio & $21.21 \pm 0.68$ & $42.81 \pm 0.91$ & $21.84 \pm 0.98$ \\
\hline
\end{tabular}

\section{Conclusion}

The ICP-MS validated for measuring toxic metal levels in fish species has been built. All values of LOD, LOQ, Recovery, and matrix effect indicated the ICP-MS method is perfectly suited for determining trace amounts of metal in fish. This study demonstrated the presence of trace toxic metal concentration in fish species, which are the most commonly consumed by Ho Chi Minh city's habitant. This study showed that the mean poisonous metal concentrations in freshwater fish species' muscle were below consumer safety. 


\section{References}

[1] Tamele, I. J., Vázquez Loureiro, P. (2020). Lead, Mercury and Cadmium in Fish and Shellfish from the Indian Ocean and Red Sea (African Countries): Public Health Challenges. J Mar Sci Eng 8:344. https://doi.org/10.3390/jmse8050344.

[2] Flora, G., Gupta, D., Tiwari, A. (2012). Toxicity of lead: a review with recent updates. Interdiscip Toxicol, 5: 47-58. https://doi.org/10.2478/v10102-012-0009-2.

[3] Allen, T., Singhal R., Rana, S. V. S. (2004). Resistance to Oxidative Stress in a Freshwater Fish Channa punctatus After Exposure to Inorganic Arsenic. Biol Trace Elem Res., 98: 63-72. https://doi.org/10.1385/BTER:98:1:63.

[4] Allen, T., Rana, S. V. S. (2004). Effect of Arsenic (AsIII) on Glutathione-Dependent Enzymes in Liver and Kidney of the Freshwater Fish Channa punctatus. Biol Trace Elem Res., 100: 039-048. https://doi.org/10.1385/BTER:100:1:039.

[5] Sangeeta Das. (2012). Toxicological effects of arsenic exposure in a freshwater teleost fish, Channa punctatus. AFRICAN J Biotechnol, 11. https://doi.org/10.5897/AJB11.2808.

[6] Shaw, J. R., Jackson, B., Gabor, K., et al. (2007). The Influence of Exposure History on Arsenic Accumulation and Toxicity in the Killifish, Fundulus Heteroclitus. Environ Toxicol Chem., 26: 2704. https://doi.org/10.1897/07-032.1.

[7] Tsai, J.-W., Huang, Y.-H., Chen, W.-Y., Liao, C.-M. (2012). Detoxification and bioregulation are critical for long-term waterborne arsenic exposure risk assessment for tilapia. Environ Monit Assess., 184: 561-572. https://doi.org/10.1007/s10661-011-1988-8.

[8] Kumari, B., Ahsan, J. (2011). Study of muscle glycogen content in both sexes of an Indian teleost Clarias batrachus (Linn.) exposed to different concentrations of Arsenic. Fish Physiol Biochem., 37: 161-167. https://doi.org/10.1007/s10695-010-9427-2.

[9] De Smet, H., Blust, R. (2001). Stress Responses and Changes in Protein Metabolism in Carp Cyprinus carpio during Cadmium Exposure. Ecotoxicol Environ Saf., 48: 255-262. https://doi.org/10.1006/eesa.2000.2011.

[10] Lemaire-Gony, S., Lemaire, P. (1992). Interactive effects of cadmium and benzo(a)pyrene on cellular structure and biotransformation enzymes of the liver of the European eel Anguilla anguilla. Aquat Toxicol., 22: 145-159. https://doi.org/10.1016/0166-445X(92)90029-M.

[11] Grose, E. C., Richards, J. H., Jaskot, R. H., et al. (1987). Glutathione peroxidase and glutathione transferase activity in rat lung and liver following cadmium inhalation. Toxicology, 44: 171-179. https://doi.org/10.1016/0300-483X(87)90147-8.

[12] Sevcikova, M., Modra, H., Slaninova, A., Svobodova, Z. (2011). Metals as a cause of oxidative stress in fish: a review. Vet Med (Praha)., 56: 537-546. https://doi.org/10.17221/4272-VETMED.

[13] Kovarova, J., Celechovska, O., Kizek, R., et al. (2009). Effect of metals, with special attention of Cd, content of the Svitava and Svratka rivers on levels of thiol compounds in fish liver and their use as biochemical markers. Neuro Endocrinol Lett 30 Suppl., 1: 169-76.

[14] Cao, L., Huang, W., Liu, J., et al. (2010). Accumulation and oxidative stress biomarkers in Japanese flounder larvae and juveniles under chronic cadmium exposure. Comp Biochem Physiol Part C Toxicol Pharmacol., 151: 386-392. https://doi.org/10.1016/j.cbpc.2010.01.004.

[15] Ay, O., Kalay, M., Tamer, L., Canli, M. (1999). Copper and Lead Accumulation in Tissues of a Freshwater Fish Tilapia zillii and Its Effects on the Branchial Na, K-ATPase Activity. Bull Environ Contam Toxicol., 62: 160-168. https://doi.org/10.1007/s001289900855.

[16] Ribeiro, A. M., Risso, W. E., Fernandes, M. N., Martinez, C. B. R. (2014). Lead accumulation and its effects on the branchial physiology of Prochilodus lineatus. Fish Physiol Biochem., 40: 645-657. https://doi.org/10.1007/s10695-013-9873-8.

[17] Reid, S. D., McDonald, D. G. (1991). Metal Binding Activity of the Gills of Rainbow Trout (Oncorhynchus mykiss). Can J Fish Aquat Sci., 48: 1061-1068. https://doi.org/10.1139/f91-125.

[18] Low, K. H., Zain, S. M., Abas, M. R. (2011). Evaluation of Metal Concentrations in Red Tilapia (Oreochromis spp) from Three Sampling Sites in Jelebu, Malaysia Using Principal Component Analysis. Food Anal Methods, 4: 276-285. https://doi.org/10.1007/s12161-010-9166-0.

[19] Thang, N. Q., Huy, B. T., Van Tan, L., Phuong, N. T. K. (2017). Lead and Arsenic Accumulation and Its Effects on Plasma Cortisol Levels in Oreochromis sp. Bull Environ Contam Toxicol., 99: 187-193. https://doi.org/10.1007/s00128-017-2113-7.

[20] Jovičić, K., Nikolić, D. M., Višnjić-Jeftić, Ž., et al. (2015). Mapping differential elemental accumulation in fish tissues: assessment of metal and trace element concentrations in wels catfish (Silurus glanis) from the Danube River by ICP-MS. Environ Sci Pollut Res Int., 22: 3820-7. https://doi.org/10.1007/s11356-014-3636-7.

[21] Has-Schön, E., Bogut, I., Vuković, R., et al. (2015). Distribution and age-related bioaccumulation of lead (Pb), mercury (Hg), cadmium (Cd), and arsenic (As) in tissues of common carp (Cyprinus carpio) and European catfish (Sylurus glanis) from the Buško Blato reservoir (Bosnia and Herzegovina). Chemosphere, 135: 289-296. https://doi.org/10.1016/j.chemosphere. 2015.04.015.

[22] Evans, D. W., Dodoo, D. K., Hanson, P. J. (1993). Trace element concentrations in fish livers: Implications of variations with fish size in pollution monitoring. Mar Pollut Bull., 26: 329-334. https://doi.org/10.1016/0025-326X(93)90576-6. 
[23] Amiard, J., Amiard-Triquet, C., Barka, S., et al. (2006). Metallothioneins in aquatic invertebrates: Their role in metal detoxification and their use as biomarkers. Aquat Toxicol., 76: 160-202. https://doi.org/10.1016/j.aquatox.2005.08.015.

[24] Kumari, B., Kumar, V., Sinha, A. K., et al. (2017). Toxicology of arsenic in fish and aquatic systems. Environ Chem Lett., 15: 43-64. https://doi.org/10.1007/s10311-016-0588-9.

[25] Thang, N. Q., Phuong, N. T. K., Van Tan, L. (2017). Endocrine stress response in Oreochromis sp. from exposure to waterborne cadmium: the plasma cortisol analysis. Toxicol Environ Chem., 99: 285-293. https://doi.org/10.1080/02772248. 2016.1172583.

[26] Tulasi, S. J., Reddy, P. U. M., Ramana Rao, J. V. (1992). Accumulation of lead and effects on total lipids and lipid derivatives in the freshwater fish Anabas testudineus (Bloch). Ecotoxicol Environ Saf., 23: 33-38. https://doi.org/10.1016/0147-6513(92)90019-Y.

[27] Allen, P. (1994). Accumulation profiles of lead and the influence of Cadmium and Mercury in Oreochromis aureus (Steindachner) during Chronic exposure. Toxicol Environ Chem., 44: 101-112. https://doi.org/10.1080/02772249409358048.

[28] Claiborne, J. B., Edwards, S. L., Morrison-Shetlar, A. I. (2002). Acid-base regulation in fishes: cellular and molecular mechanisms. J Exp Zool., 293: 302-319. https://doi.org/10.1002/jez.10125.

[29] Gonick, H. C. (2011). Lead-Binding Proteins: A Review. J Toxicol., 2011: 1-10. https://doi.org/10.1155/2011/686050. 